\title{
Research on Innovative Training Mode of Chinese Academic Postgraduates
}

\author{
G. L. Liu
}

\begin{abstract}
In today's society, Chinese academic postgraduates are required to have not only technological capabilities, but also good personal credit, vocational abilities and the high professional qualities to take complete charge by fast learning. However, the traditional training mode of Chinese academic postgraduates has not been effectively combined with students' future careers. As a result, it is hard for the postgraduates to meet actual needs of job markets. The arrival of the era of big data provides an unprecedented opportunity for innovative training of Chinese academic postgraduates. In this paper, an innovative training mode guided by vocational abilities is proposed based on big data analysis to improve the competitiveness of Chinese academic postgraduates in talent markets. Firstly, honesty education should be strengthened. Secondly, advanced teaching methods based on big data analysis should be introduced. Thirdly, the design of individualized vocational ability training programs should be supplied for each academic postgraduate based upon the data statistics and analysis of graduates' information. Finally, behavior analysis based on big data should be used to provide early warning of mental health problems for postgraduates.
\end{abstract}

Index Terms-Big data, Chinese academic postgraduate, training mode.

\section{INTRODUCTION}

Now we are in a rapidly developing society, where science and technology is well developed and information flows fast. The communication among people is becoming more and more frequent and closer. And, life is more and more convenient. Big data, as a product of this high-tech era, makes today's society having new capabilities to obtain great value products and services or deep insights through the analysis of massive data. Viktor Mayer-Schönberger, known as the first man in big data business applications, prospectively pointed out that the information storm brought by big data was changing our life, work and thinking. As a result, big data was opening a major era of transformation. The most significant change in the era of big data stressed by Mayer-Schönberger is that relevant relationships will receive more and more attention and causalities will no longer be concerned.

In recent years, with the rapid development of the Internet and the information industry, big data has aroused widespread concern. Meanwhile, data is considered as a new material of the third industrial revolution. Now, we are in an

Manuscript received December 29, 2016; revised March 25, 2017. This work was supported in part by the Project of Chinese society of academic degrees and graduate education under Grant C-2015Y0501-016.

G. L. Liu is with School of Science, University of Science and Technology Liaoning, Anshan, Liaoning, 114051 China (e-mail: lg_li1978@126.com). era of information explosion, big data is full of every corner of modern society, influencing and even changing our daily life in a variety of forms. In China, the research on big data usually focuses on the physics, biology and environmental ecology used in military, financial, and telecommunications industries. At present, big data technologies are rarely used to improve the traditional training modes of students in China. But, in fact, the training modes constructed based on big data analysis can help students, especially academic postgraduates, to effectively improve their competitiveness in talent markets, which motivates our study.

\section{PRoblems Existed IN THE TRAditional TRAINING MOdE OF CHINESE ACADEMIC POSTGRADUATES}

In China, postgraduates are usually classified into academic type and professional type. Academic postgraduates refer to the graduate students cultivated for scientific research of basic theories. They are required to focus on the study of basic subjects and related knowledge to have stronger scientific research abilities. Therefore, in the course of the traditional cultivation of Chinese academic postgraduates, there is a tendency for a long term to focus on knowledge and ignore abilities, emphasize theory and neglect practice, pay more attention to inheritance rather than innovation.

In recent years, with the continuous expansion of enrollment scale and the implementation of educational system reform, the education quality and employment situation of Chinese academic postgraduates has attracted more and more attention. As noted before, the main purpose of cultivating academic postgraduates is to provide qualified talents for higher education institutions and scientific research institutions. But the survey results show that, after graduation, the academic postgraduates hoping to work in enterprises and government departments account for $40.7 \%$ and $19.6 \%$, while the proportions for universities and research institutes are only $21.8 \%$ and $17.9 \%$, respectively [1]. Since the cultivation of academic postgraduates in China mainly focuses on basic research abilities, a serious lack of the vocational abilities needed by enterprises and government departments becomes inevitable. After graduation, academic postgraduates are often confused by a series of problems which make them hard to get jobs, such as how to use what they have learned to analyze and solve practical problems, how to innovate, how to deal with practical affairs, etc. Tracing to its source, the current training mode seriously divorcing from employment intentions and thus unable to make any timely and effective response to the demands of employers and society is the main 
reason behind these problems. Moreover, economic construction as well as scientific and technological progress in China has put forward more and more extensive and diverse requirements on the education of academic postgraduates. In order to cultivate high-quality complex talents needed by the present society, the academic postgraduate education in China must be reformed and guided by vocational abilities. Therefore, it is of great theoretical and practical value to construct the innovative training mode of Chinese academic postgraduates guided by vocational abilities.

\section{CONCRETE ThOUGHTS TO CONSTRUCT THE INNOVATIVE} Training Mode of ChInese ACADEMIC PostgraduATES

Firstly, the student credit evaluation system should be established and the integrity education of Chinese academic postgraduates should be strengthened. Nowadays, in the era of big data, credit has been listed as one of the most important items to assess the candidates' vocational abilities by most enterprises. In the countries where credit system is complete and widely used, many times of subway fare evasion and other behaviors of dishonesty will affect the graduates to find jobs. The excellent graduates, who have good personal credits, professional qualities, technical abilities, and can take complete charge through fast learning, are the scarcest talents in today's society.

On May $9^{\text {th }} 2016$, the first national credit recruitment of college graduates was held in Zhejiang University, which was jointly organized by DELL, McDonald's, Qufenqi, Niudian Science \& technology and many other large enterprises. In this job fair, the credit evaluation of third-party credit agencies, such as Zhima Credit Score, had been used as an important reference for the recruitment of college graduates and interns. Zhima Credit Score is provided by Zhima Credit, which is an independent third-party credit filing and scoring service provider. As a crucial part of the Ant Financial ecosystem, Zhima Credit can objectively reflect personal credit status based on cloud computing and machine learning technologies. So far, Zhima Credit has provided credit services for users and merchants in over one hundred use cases, including credit cards, consumer finance, leasing and mortgages, hotels, house rentals, car rentals, online dating, student services, public utilities and services. Zhima Credit Score is the result of the comprehensive treatment and evaluation of the massive data from about five dimensions including credit history, behavior preference, performance ability, identity-based characteristics and personal connections. The data used by Zhima Credit originates from the e-commerce transaction data of Alibaba, the internet financial data of Ant Financial, the data provided by the ministry of public security and other public institutions as well as cooperative partners. Different from traditional credit data, those data comes from all aspects of our lives, such as credit card repayment, online shopping, transfer accounts, financing, payment records of water, electricity and gas fees, information about house renting, history of address relocation, social connections, etc [2].

Jie $\mathrm{Wu}$, the senior manager of DELL (China) personal consumption business department, said that the recruitment of representatives for DELL campus project had a higher requirement for students' personal credits. He would refer to the evaluation results of college students' credit, such as Zhima Credit Score, and so on. As well known, McDonald's is one of the best employers in China and Asia Pacific region. The McDonald's recruitment director also said that credit had been included in their ability evaluation of applicants. During the recruitment process, he would make reference to the credit evaluation of third-party credit agencies. Meanwhile, he also advocated college students to develop good credit habits and win employment opportunities by their own credits. Moreover, Qufenqi released a "Ten-million Venture Incubation Fund" to provide entrepreneurship support for the college students with good credit. You Lin, the vice-president of Qufenqi, stressed that the miracle and innovation of the Internet needed young people to be vigorous, active and trustworthy. He firmly believed that the young people with good credit will have a better future. Also, he indicated that the credit evaluations given by Zhima Credit and other third-party credit agencies had already been used as important evaluation criteria and reference factors when Qufenqi recruited talents or determined the consumption levels for their users. Furthermore, many enterprises participated in this job fair provided additional high-quality internship positions and part-time jobs for the college students with good credit. All the presented enterprises jointly launched an initiative for credit recruitment of college students: popularize credit culture, encourage credit accumulation and promote credit employment. Let the college students with good credit have better development opportunities [3].

Thus, colleges and universities should cooperate with third-party credit agencies to construct evaluation system of students' credit and strengthen students' honesty education. This will help to combat increasingly rampant cheating behaviors on campus in China, such as taking examinations or attending lectures instead of others, etc. Also, it can improve the professional qualities and vocational abilities of Chinese academic postgraduates, and therefore enhance their competitiveness in talent markets.

Secondly, online learning systems based on big data analysis should be introduced, which are very convenient for students to review what they have learned by repeatedly watching course videos. At the same time, it will also facilitate teachers to track students' learning progress and status, which can help teachers to find the best teaching methods and provide personalized guidance and recommendation in time for students. For example, if a teacher finds that most students need to watch the video of a certain course several times, he will timely know that the corresponding knowledge points haven't been mastered by the students. Then, he can promptly supplement related learning materials and recommend them to the students. In addition, practice sessions should be arranged in the online learning systems, which could propose opportunities for students to solve practical problems using what they have learned. There have been many successful cases abroad. Engel Andrew, a professor of Stanford University, had realized two functions in his online learning system for machine learning courses after collecting the massive data 
about the forum posts red by students and the correct rates of students completing their homework. One is using big data analysis to predict the probability that students can give correct answers after reading a post. The other is to determine which posts are suitable for students to read and then recommend them to the students [4]. Canadian educational technology company, "Desire to Learn", also launched a big data service project for universities to forecast and improve the academic records of students based on their past data. In this project, teachers can monitor the electronic curriculum materials red by students and communicate with students online, while students can submit their electronic coursework and complete examinations and tests on line. All these records are stored and analyzed continuously and systematically by computer programs to help teachers diagnosing problems in time, making recommendations for improvement and predicting examination scores.

Obviously, advanced teaching patterns based on big data analysis can effectively make up for the defects of traditional teaching methods and improve the self-learning ability and learning efficiency of students. Also, it can effectively improve the practical innovation ability of students.

Thirdly, the database of graduate information should be renewed, perfected and statistically analyzed to provide personalized recommendations for internal students to cultivate their vocational abilities. At present, many universities only retain the graduate information in recent years and not updated it year by year. Thus, most of the contact information and working situations are changed and useless. In fact, if the various performances of graduates in school and their employment information could be preserved and updated year by year, a very valuable big data will be formed. Based on the analysis of this big data, the specific correlations among vocational abilities, success rate of employment and various performances in school can be established. On the basis of these correlations, valuable and exclusive recommendations for occupational planning and the selection of specific courses and research directions can be provided for each student. Also, these correlations can help instructors to revise training schemes, teach students in accordance with their aptitude and design individualized training programs for each student according to his occupational planning, which will effectively improve the professional quality and vocational abilities of students and therefore enhance the probabilities of their successful employment in future.

Finally, the behavior analysis based on big data should be used to provide students with timely psychological health counseling which could escort for healthy growth and successful employment of students. Contemporary college students have the characteristics of broad vision, active thinking and rich emotion. Their abilities of rational analysis are strong and their features of logical thinking are prominent, but their thinking is relatively narrow and rigid. This usually makes their behaviors not gregarious and therefore makes them facing a lot of psychological problems and conflicts. Once they are affected by external adverse factors, they are prone to psychological disorders or serious pathological psychological problems. That will not only affect their characters, health and making friends, but also seriously affect their development and employment. This is especially the case for academic postgraduates. How to discover the mental health problems of students and provide timely help, especially for academic postgraduates, has become an urgent problem to be solved in China. Considering that extremely lonely students are the highest incidence group of campus mental diseases, Professor Zhou and his team had conducted an experiment to locate lonely students in University of Electronic Science and Technology of China. In their experiment, the big data composed by time records for students in canteens, entering and leaving libraries or dormitories is used. Base on the analysis of these records, they can accurately determine whether a student often goes with his friends or takes part in some outdoor sports activities, and etc. Eventually, the loneliest students successfully identified by them only in University of Electronic Science and Technology of China are more than 800 . The probability of these loneliest students suffering from mental diseases is 19 times higher than that of other students, which must be highly valued [5]. The behavioral data of students usually contains a lot of valuable real-time information. If that information can be tracked and analyzed, the mental abnormalities of students can be found and warned timely and then many tragedies could be prevented. Therefore, the behavior analysis based on big data is of vital importance in ensuring the healthy growth and successful employment of students, particularly for academic postgraduates.

\section{CONCLUSION}

With the rapid development of information technology and mobile Internet, the costs of recording and storing data have been significantly reduced and the abilities of collecting, processing and analyzing data has been substantially enhanced. The era of big data has already come. At present, the research on big data in China is mainly focused on the fields of physics, biology and environmental ecology. Still, there is little research on applying big data analysis in improving the training modes of students. Such research is even scarcer for academic postgraduates who extremely lack vocational abilities. Therefore, in this paper, we propose an innovative training mode of Chinese academic postgraduates which is guided by vocational abilities and based on big data analysis. The main ideas are described from four aspects, i.e. education of personal qualities, teaching methods, personalized design of training schemes and early warning mechanism of mental health. In the future, we will further study the specific implementation of this training mode.

\section{REFERENCES}

[1] L. L. Hu and W. L. Pan, "Investigation and countermeasures for the training modes of academic and professional postgraduates," Research in Educational Development, vol. 25, pp. 20-23, October 2005.

[2] Z. J. Xinhuanet. (January 2015). Testing the water in personal credit: Zhima Credit launched the first personal credit score in China. [Online]. Available:

http://www.zj.xinhuanet.com/finance/2015-01/28/c_1114164007.htm

[3] Chinanews. (May 2016). DELL, McDonald's, Qufenqi and many other large enterprises introduces credit rating into campus recruitment for the first time. [Online]. Available: http://www.chinanews.com/business/2016/05-10/7864715.shtml 
[4] V. Mayer-Schönberger and K. Cukier. Big Data: A Revolution Tha Will Transform How We Live, Work and think, H. Y. Sheng and T. Zhou, Tr. Hangzhou: Zhejiang People's Publishing House, 2015, p. 149.

[5] T. Zhou. Big Data Innovation, Beijing: Beijing Joint Publishing Company, 2016, pp. 113-122.

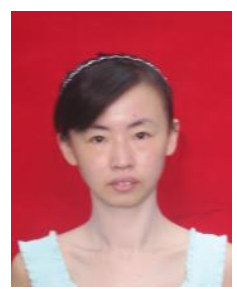

G. L. Liu was born in Benxi, Liaoning, China, in 1978. She got the doctor degree of systems engineering in 2008, from Northeastern University, Shenyang, China. Her major academic interests include inventory management, order scheduling, supply chain management and combinatorial optimization, and education. 